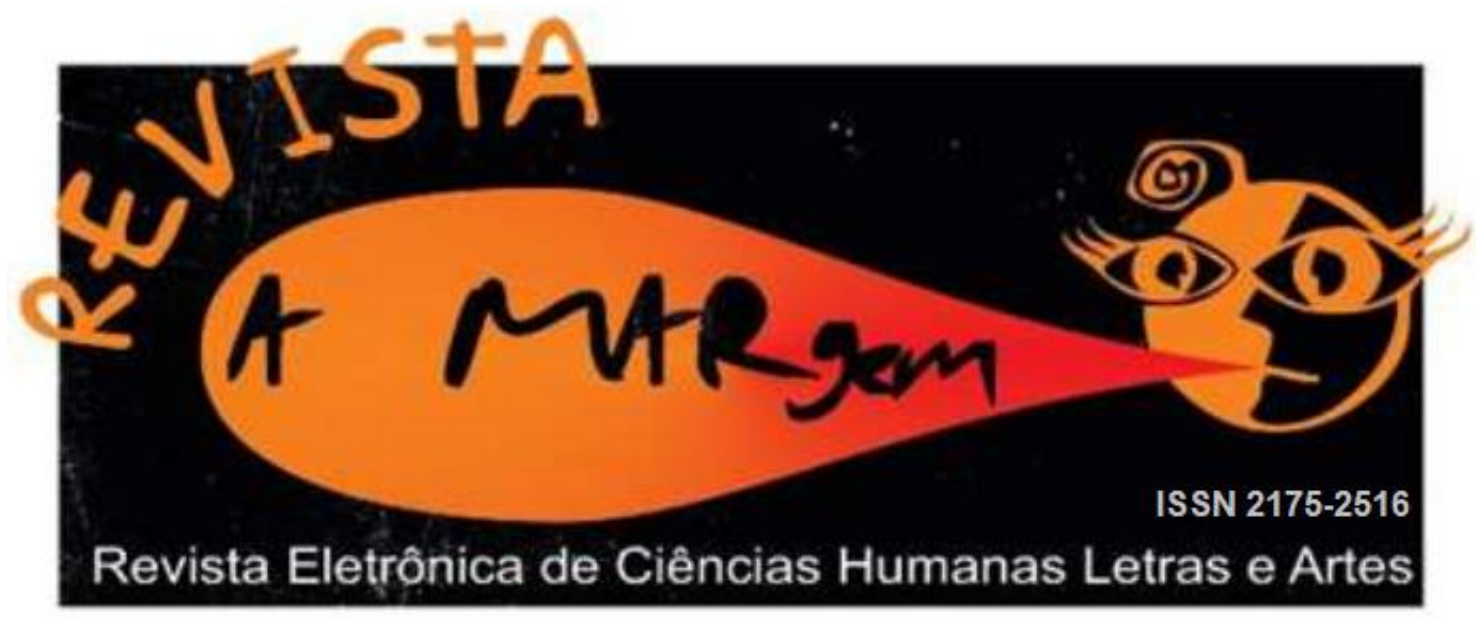

\title{
RESIDÊNCIA PEDAGÓGICA NA FORMAÇÃO DO ALUNO DE LETRAS- ESPANHOL DA UFPB
}

\author{
Mayra Suézia Oliveira dos Santos \\ Universidade Federal da Paraíba - UFPB
}

Resumo: Considerando que o Residência Pedagógica (RP) - pioneiro entre 2018 e 2020 - é um programa que se volta ao aperfeiçoamento da formação docente, trataremos de explicitar e discutir pontualmente as atividades realizadas durante a sua execução em uma escola pública de Ensino Médio, Integral e Técnico, localizada em Bayeux, PB. Os objetivos são: (i) narrar as atividades realizadas e (ii) refletir se o RP contribuiu com a formação do aluno de Letrasespanhol da Universidade Federal da Paraíba, UFPB. Para tanto, a nossa metodologia se deu por meio de observações: de aulas de espanhol e do contexto escolar, como também através das regências de aulas e da elaboração e aplicação de um plano de ação - o que nos leva a uma pesquisa-ação (TRIPP, 2005), de natureza qualitativa. Nos fundamentamos em autores e documentos que dialogam sobre o RP, sobre o ensino de línguas estrangeiras e a formação docente, a saber: Brasil (1998; 2006), Leffa (1999), Moreno Fernández (2005), Biazi, Gimenez e Stuts (2011), Silva (2012), Costa e Fontoura (2015) e BNCC (2018). Concluímos que o RP contribuiu com a formação do licenciando, uma vez que o coloca em ação com a teoria vista na academia e a prática vivida na escola. Os resultados mostram que foi possível refletir positivamente acerca da formação docente propiciada pelas atividades realizadas no RP.

Palavras-chave: Residência Pedagógica; Formação docente; Espanhol; Ensino Médio.

\section{Residencia pedagógica en la formación del alumno de letras-español de UFPB}

Resumen: Considerando que el Residencia Pedagógica (RP) - pionero entre 2018 y 2020 - es un programa que tiene el propósito de mejorar la formación docente, trataremos de explicitar y discutir brevemente las actividades que se realizaron durante su ejecución en una escuela pública de Enseñanza Secundaria, Integral y Técnica que se ubica en Bayeux, PB. Los objetivos son: (i) narrar las actividades que se realizaron y (ii) reflexionar si el RP contribuyó con la formación del alumno de Letras-español de la Universidade Federal da Paraíba, UFPB. Para tanto, nuestra metodología se llevó a cabo a través de observaciones: de clases de español y del contexto escolar, así como de regencias de clases y de la elaboración de un plan de acción - lo que nos conduce a una investigación-acción (TRIPP, 2005), de naturaleza cualitativa. Nos fundamentamos en autores y documentos que dialogan sobre el RP, sobre la enseñanza de lenguas extranjeras y la formación docente, a saber: Brasil (1998; 2006), Leffa (1999), Moreno Fernández (2005), Biazi, Gimenez y Stuts (2011), Silva (2012), Costa y Fontoura (2015) y BNCC (2018). Concluimos que el RP contribuyó con la formación del licenciando, ya que lo 
pone en acción con la teoría que se ve en la academia y la práctica que se vive en la escuela. Los resultados muestran que se hizo posible reflexionar positivamente acerca de la formación docente que propició la realización de las actividades del RP.

Palabras-clave: Residencia Pedagógica; Formación docente; Español; Enseñanza secundaria.

\section{Reflexões iniciais vivenciadas no Ensino Médio}

O Residência Pedagógica é um programa voltado ao aperfeiçoamento dos discentes futuros professores - dos cursos de licenciatura. Seu objetivo geral é contribuir com esta formação através de projetos que promovam a união entre a teoria vista na academia e a prática vivenciada na escola de Educação Básica (EB). Seus objetivos específicos buscam reformular os estágios supervisionados dos cursos de licenciatura; aproximar a relação entre escola e academia; e promover e contribuir com a adequação do currículo e propostas pedagógicas dos cursos de formação inicial de professores de EB (CAPES, 2018).

De acordo com Costa e Fontoura (2015), o programa Residência Pedagógica (RP) possibilitaria ao aluno-professor um "período diferenciado de atuação profissional, um período pré-definido de encontros de reflexão sobre a prática docente e atuação em parceria com um professor regente, e não uma etapa ou avaliação dentro do estágio probatório" (COSTA; FONTOURA, 2015, p. 164).

Logo, ao nos colocarmos nesta posição de parceria com a professora preceptora, assumimos a função de residente pedagógica (futura professora) e a função de aluna graduanda em Letras (Língua Espanhola) pela Universidade Federal da Paraíba (UFPB).

A escola onde colocamos em prática nossa vivência docente se trata de uma instituição Cidadã-Integral-Técnica que se localiza no bairro do Sesi, na cidade de Bayeux, e possuía em torno de 480 alunos que são estudantes de período integral, matriculados nos cursos técnicos de mecânica ou designe de móveis. Para ingressar nesta escola os alunos passaram por um processo seletivo que utilizou as suas notas do ensino fundamental como critério de classificação. Na época da execução do programa RP (agosto de 2018 a janeiro de 2020), a escola possuía 6 (seis) turmas de cada curso técnico.

Na medida do possível, a escola tentava proporcionar uma formação de excelência e suprir demais necessidades da comunidade escolar. As aulas iniciavam às 07h30 (sete e meia) e terminavam às $17 \mathrm{~h}$ (dezessete horas), havendo três momentos de intervalo durante as refeições: (1) o primeiro lanche era servido das 09h30 (nove e meia) às 09h50 (nove e cinquenta), (2) o segundo momento era dedicado ao almoço que começava às $12 \mathrm{~h}$ (doze horas) 
e terminava às $13 \mathrm{~h} 20$ (treze e vinte) e o (3) terceiro e último momento de lanche começava às 15h (quinze horas) e terminava às $15 \mathrm{~h} 20$ (quinze e vinte).

Dito isto, as aulas duravam 50 (cinquenta) minutos, cada. Especialmente sobre as aulas de Língua Espanhola - disciplina de nossa formação acadêmica, as mesmas aconteciam uma vez por semana em cada uma das turmas. Na parte da manhã, eram regidas 5 (cinco) aulas e na parte da tarde, eram administradas 4 (quatro), somando 9 (nove) aulas por dia.

No que se refere aos eixos fundamentais aos quais a escola estava fundamentada, como escola cidadã integral, buscava oferecer uma educação que possibilitasse ao educando não só uma formação acadêmica por excelência, como também para a vida e para o desenvolvimento das competências para o século $\mathrm{XXI}^{1}$.

Em razão disso, as disciplinas eram separadas em três blocos: (1) disciplinas de básico I (como português e matemática), disciplinas da área profissional (línguas estrangeiras, a título de exemplo) e (3) as disciplinas técnicas. Os alunos ainda possuíam algumas disciplinas e projetos que formam parte da base diversificada do currículo, como a formação de clubes de teatro, futebol, xadrez, entre outros. Também participavam de tutorias, acolhimentos, projeto de vida (leituras e reflexões), avalição semanal (provas objetivas de até três disciplinas), estudo orientado (um colega ensina ao outro, visando o autodidatismo), protagonismo juvenil (palestras realizadas pelos próprios alunos) e eletivas (temáticas oferecidas semestralmente e que se integram a alguns subprojetos e subgrupos). Outro ponto importante eram as guias de aprendizagem que explicitam como e quais são os objetivos das avaliações a serem feitas, podendo-se alterá-las a partir das sugestões dos alunos.

Em todas as disciplinas as notas eram obtidas através da avaliação semanal. Especificamente na disciplina de Língua Espanhola, trabalhos escritos ou orais e a participação em projetos (que podiam ser abertos ou não para a comunidade externa à escola) também eram critérios de avaliação que faziam parte da soma e da divisão de duas notas.

Para concluir esta seção, caracterizaremos, brevemente, o nosso projeto. Este último foi de caráter multidisciplinar porque englobava professores e alunos de Letras-Inglês e LetrasEspanhol da UFPB e das três escolas contempladas (sendo duas localizadas na cidade de Bayeux e uma localizada em João Pessoa). Para isso, discutíamos e refletíamos acerca de textos e documentos que tratam do ensino de línguas estrangeiras dentro do atual contexto de nosso país, fazendo-se necessário reportar discussões passadas e, assim, tecer comentários sobre os principais pontos e/ou aspectos que impactaram a nossa leitura.

\footnotetext{
${ }^{1}$ Disponível em: http://porvir.org/conheca-competencias-para-seculo-21/. Acesso em 20 de outubro de 2018.
} 
Sendo assim, era por meio das discussões ocorridas durante as reuniões quinzenais (nas quais nos reunimos para discutir os textos lidos e receber orientações dos professores orientadores de núcleo), dos trabalhos escritos - comentários e relatos críticos, por exemplo ou, ainda, a partir de nossas próprias observações das aulas na escola, que procurávamos fazer a relação entre a teoria e a prática.

Além disso, elaboramos um plano de ação para o contexto específico da(s) turma(s) observada(s). Esse plano possivelmente contribuiu com a aprendizagem da língua meta, solucionando as dificuldades diagnosticadas durante a fase de observações. Também tivemos a oportunidade de reger as aulas oriundas de nossa proposta de ação (em parceria com a Professora Preceptora (PP)) e, assim, obtivemos resultados que nos proporcionaram conclusões mais detalhadas a respeito de nossa prática e experiência docente na EB, o que nos leva aos objetivos deste trabalho: (i) narrar as atividades realizadas e (ii) refletir sobre a sua contribuição na formação do aluno de Letras-espanhol da Universidade Federal da Paraíba, UFPB.

Em suma, pretendemos narrar para mostrar-lhes como foram as atividades realizadas durante a vigência do programa supracitado - levando em conta que estamos caracterizando um programa pioneiro e que o fato de expor a nossa reflexão pode instigar todos aqueles que se interessem no assunto.

Além do mais, esclarecemos que devido a nossa metodologia se tratar de uma pesquisaação e ser de natureza qualitativa, uma vez que estamos nos baseando nas nossas observações e impressões acerca da nossa experiência docente no ambiente escolar mencionado, pode haver falta de clareza em algumas descrições (as fases do projeto) e/ou reflexões - que se deu em razão da ampla variedade de atividades desenvolvidas ao longo do RP, algo que se torna difícil de segregar, já que tudo acontecia de forma interligada e, quase sempre, simultaneamente.

Enfim, passaremos para as próxima seções. Este artigo contêm um capítulo sobre as principais atividades realizadas no RP; um capítulo descritivo das fases do referido programa; um capítulo reflexivo com base em leituras das áreas de ensino de línguas e formação docente; e, por último, as considerações finais.

\section{Caminhos percorridos durante o Residência Pedagógica: vivenciando a prática}

Inicialmente, o projeto se desenvolveu a partir de observações realizadas nas turmas. A observação de aulas foi realizada, quase que semanalmente, nos dias em que havia regência escolar (mas também podíamos observar e ir à escola em outros dias) da professora preceptora. A escolha do dia para observar aulas foi feita pela professora preceptora, conforme a nossa 
disponibilidade de horário, que nos dividiu em grupos de observação. Isso quer dizer que observávamos as suas aulas e pontuávamos em nossos relatos reflexivos de observação determinado ponto que nos havia chamado a atenção. Também alguns eventos (apresentações, atividades desenvolvidas e imprevistos do meio escolar) ocorridos fora da sala de aula ganharam espaço nesse processo de observação/ambientação.

Consoante a isso, vale dizer que foi desde o nosso primeiro contato com as turmas observadas $\left(1^{\circ} \mathrm{AM}, 1^{\circ} \mathrm{AD}, 1^{\circ} \mathrm{BM}, 1^{\circ} \mathrm{BD}, 2^{\circ} \mathrm{BM}\right.$ e $\left.3^{\circ} \mathrm{BM}\right)$, principalmente a terceira e a última turmas (pois foram as turmas que mais tivemos contato), que construímos, pouco a pouco, expectativas e identidades docentes (aprender a ser professor). Aliás, compreender como funciona uma escola desse modelo, como se constrói a relação entre alunos e professores e, ainda, como elaborar propostas de atividades dentro de um contexto tão específico, foi uma experiência ímpar para a nossa formação de futuros professores de espanhol.

Entendemos que um professor é um profissional que deve possuir uma postura reflexiva e contínua dessa formação, compreendendo que existe um contexto específico de ação e que a observação é, na verdade, uma troca de experiências entre o observador e o observado (BIAZI; GIMENEZ; STUTS, 2011). Nessa perspectiva, a maneira como a PP de língua espanhola interagia com todos os alunos residentes (AR) foi primordial para o nosso engajamento durante as observações. Por ela ser bastante aberta a sugestões - empática - isso facilitava e contribuía com a nossa desenvoltura dentro e fora da sala de aula. Foi por meio dessa troca de experiências entre a PP e nós, AR, que desenvolvemos e/ou elaboramos, finalmente, a(s) minha(nossas) proposta(s) de atividade(s) (ler-se plano de ação).

A elaboração de nosso plano de ação/intervenção nasceu da discussão em como cativar a participação dos alunos para aproximarem-se da língua alvo, pois levamos em conta que se realizaria nos últimos 30 minutos do intervalo para o almoço - como a escola era de período integral, não tínhamos outras opções de horários, especialmente porque já estavam destinados a aulas e projetos para a comunidade. Encontramos, ao longo de sua execução, muitos (enfatizamos) contratempos que interferiram consideravelmente nos resultados, pois outros eventos acabaram acontecendo em concomitância com o horário de nosso projeto. Isso implicou no resultado final, uma vez que, durante os seis encontros que realizamos, os alunos mais assíduos também estavam envolvidos nessas atividades, acarretando atrasos (lembrando que o tempo já era curto) ou ausências. Como não tínhamos outro horário disponível para realiza-lo, tivemos que nos adaptar a essa realidade. Passaremos a descrevê-lo.

O plano de intervenção “¿Vamos a oír canciones en español?” foi produzido e executado em conjunto com outros 3 alunos residentes no período de julho a agosto de 2019, totalizando 
6 encontros semanais de 30 minutos. Em cada um desses encontros, escolhemos músicas de países/culturas distintos(as) do espanhol, a saber: Peru, Porto Rico, Colômbia, México, Argentina e Espanha, respectivamente.

O objetivo geral foi discutir sobre as temáticas das músicas em língua espanhola. Os objetivos específicos foram: (i) exercitar a modalidade de escuta/compreensão em língua espanhola; (ii) interpretar (criticamente) músicas em língua espanhola; (iii) perceber o uso do recurso audiovisual como construtor de sentidos variados; (iv) discutir em língua espanhola sobre os temas abordados nas músicas escolhidas.

No primeiro encontro explicamos aos alunos participantes como iria funcionar o projeto (também chamado de oficina de música). Avisamos que dos 21 países que têm o espanhol como língua oficial, sortearíamos dois países por semana para que uma enquete fosse realizada e eles, por meio dessa votação, escolhessem o país de preferência. Finalmente, o país mais votado seria o escolhido e nós, alunos residentes, pensaríamos em uma música para a discussão.

Além disso, ainda no primeiro encontro levamos uma música da variedade peruana que se intitula "La bicicleta" (Carlos Vives). A temática remetia a infância, e o estilo lembrava muito o reggae. A ideia de abordar esse tema e de apresentar esse estilo de música foi propiciar boas recordações sobre essa época da vida, fazendo com que os estudantes criassem o sentimento de valoração a partir do contraste com a vida adulta (que é bem mais conturbada e exige mais responsabilidades) e desmistificar possíveis preconceitos, mostrando-lhes que qualquer estilo musical é capaz de possibilitar uma abertura para discutir quaisquer temas, não restringindo-se a um determinado grupo social.

No segundo encontro levamos a música que se intitula "Tu foto" e, através da interpretação de Ozuna, discutimos questões fonético-fonológicas, linguísticas, multimodais (também exibimos o clipe oficial da música) e, claro, o que mais lhes chamou a atenção: o tema. A temática trouxe à tona a foto como elemento de recordação capaz de suscitar memórias que se associam aos entes queridos. Também observou-se o comportamento das pessoas que conviviam com esses entes queridos, que no vídeo ficou mais claro, já que várias interpretações pairaram sobre o fato de que as pessoas que continuavam vivas tinham certos vícios (alcoolismo, droga e crime), entendidos como a causa da morte desses entes. O outro sentido discutido foi sobre a mudança de comportamento (regenerativo) pós-morte dessas mesmas pessoas. O objetivo foi provocar essa reflexão nos alunos e fazê-los valorizar as suas relações familiares. Quanto ao estilo musical, se tratou de um pop e o levamos para mostrar-lhes que o tipo de música que eles mais costumam ouvir, muitas vezes só prestando atenção ao ritmo acelerado, também pode trazer assuntos sérios para serem refletidos. 
No terceiro encontro a música escolhida foi "Robarte un beso" (Sabastian Yatra e Carlos Vives). Com essa música discutimos como um beijo carinhoso poderia ressignificar um elo de carinho entre nós e as pessoas que conosco convivem: pais, irmãos, amigos, avós, tios etc. Os alunos trouxeram exemplos de suas próprias vidas para a discussão e relataram que nunca haviam pensado nisso como forma de afeto diário, principalmente levando em conta que eles passavam o dia inteiro na escola e que muitas vezes só viam essas pessoas especiais durante a noite e/ou esporadicamente. O estilo dessa canção lembrava o sertanejo de raiz que há em nosso país. O escolhemos, porque esse estilo transmite um ar de delicadeza a linguagem poética, aumentando a sensibilidade de quem a escuta.

No quarto encontro levamos a canção "Aún hay algo", interpretada pelo grupo mexicano Rebeldes. Mais uma vez a temática nos levou a falar sobre sentimentos, mas dessa vez falamos sobre um sentimento de despedida, de uma relação afetiva que, por desistência de ambas as pessoas, não prosseguiu. Discutimos que apesar dessa separação, continuou existindo o afeto entre elas e, sendo assim, podemos escutar dos alunos que se algo é importante, seja uma relação afetiva ou não, não se deve desistir. O estilo musical foi o pop/rock romântico e optamos por isso porque trouxe um outro tipo de conhecimento musical vindo do México para além dos mais conhecidos.

No quinto e penúltimo encontro levamos as músicas "See you" (Pilar Pascual e Renata Toscano) e "Bailando" (Enrique Iglesias). A primeira falava do processo de crescer e como é duro passar por isso e, ao mesmo tempo, ter que lidar com escolhas e consequências. A segunda falava mais da conexão entre duas pessoas em meio ao jogo de paquera. Escolhemos essas músicas porque enquanto uma nos favoreceu um debate sobre escolhas pessoais; a outra se configurou como meio para discutir um tema totalmente presente na faixa etárias desses alunos, pois muitas vezes eles querem falar sobre isso, mas não têm uma abertura e, portanto, achamos válido trazer esse tema à tona de uma forma simples, já que a música foi discutida do ponto de vista do eu lírico (que somente contemplava o ser amado de longe).

Vale dizer que durante os encontros fazíamos a leitura interpretativa da letra da música, exibíamos o videoclipe - trabalhando a multimodalidade a partir do audiovisual, colaborando com a construção de sentido do texto (letra da música) - e ouvíamos a canção (explicávamos aspectos fonético-fonológicos), além de ter solicitado a produção de um vídeo temático de opinião sobre uma das músicas abordadas, incentivando, assim, a produção oral.

Para a finalização do projeto, no sexto e último encontro, organizamos um karaokê, no qual cantamos, dublamos e discutimos a experiência de ter participado/realizado esta oficina. Os resultado mais marcante foi a apresentação elaborada por um dos alunos, uma vez que ele 
criou uma coreografia especialmente para esse momento, inspirada em canções discutidas durante os encontros.

Além dos objetivos almejados, conseguimos trabalhar as inteligências corporalcenestésica e musical, corroborando com a ideia de que a música possui uma linguagem universal e cultural, quando associada aos contextos cotidianos. Tendo em vista isso, podemos afirmar que os resultados foram positivos (apesar das dificuldades). Conseguimos, a partir das temáticas abordadas através das músicas, trabalhar um pouco de cada um dos objetivos supracitados.

Os alunos melhoraram a fluidez e aprimoraram a leitura crítica-interpretativa (passando a organizar as ideias de forma mais clara e considerando os elementos presentes no videoclipe). Os alunos entenderam que o texto visual (ou audiovisual) influenciou muito o sentido da interpretação que se tinha da letra da música e, sendo assim, ambas formas de interpretação começaram a fazer parte de seus diálogos com muito mais significado). Diferentemente, também conheceram determinados aspectos fonético-fonológicos e culturais.

Fazendo um levantamento numérico, avaliamos que 50\% dos alunos assíduos também conseguiram se comunicar em espanhol de forma bem mais clara e fluida (os outros 50\% também melhoram muito, mas por terem faltado alguns encontros apresentaram um pouco mais de dificuldade) e, pelas vários contratempos no decorrer da execução, compreendemos que esses resultados são bastante animadores, de modo que o projeto conseguiu alcançar o mínimo para o cumprimento dos objetivos almejados.

Enfim, passaremos agora a relatar as fases das atividades realizadas na escola.

\section{Caminhos percorridos durante o Residência Pedagógica: vivenciando a reflexão}

As tarefas realizadas no projeto e as intervenções realizadas na escola advieram das observações e das reflexões feitas acerca do contexto do ambiente escolar.

$\mathrm{Na}$ primeira fase, que diz respeito às três primeiras visitas à escola, averiguamos as condições de infraestrutura (aqui incluímos condições físicas de salas, equipamentos, laboratórios, biblioteca, quadra de esportes, sala dos professores etc.); a presença de projetos ofertados pela instituição; o possível vínculo de outros profissionais com a escola, como psicólogos e assistentes sociais, como também empresas públicas e privadas; a disponibilidade de recursos pedagógicos (além do livro didático); e a existência de regimento, normas internas e Projeto Político Pedagógico. 
$\mathrm{Na}$ segunda fase, relatávamos e refletíamos sobre as nossas impressões. Vale ressaltar que desde o começo participamos de reuniões de formação que aconteciam, aproximadamente, a cada quinze dias. Nessas reuniões, discutíamos, através de comentários críticos feitos pelos próprios $\mathrm{AR}$, os textos disponibilizados (detalhados no decorrer das próximas seções) pelas professoras orientadoras do Núcleo RP Letras-Inglês/Letras-Espanhol.

$\mathrm{Na}$ terceira fase, executamos 100 horas de regência escolar - a seleção de turmas nesta fase se deu razão da nossa disponibilidade de horário em relação ao horário de aula imposto pela escola. Inicialmente, estávamos apreensivos por esse momento inédito de nossa primeira experiência docente. Vivenciamos um mundo de descobertas durante cada aula regida, pois acreditamos que o professor (principalmente em formação) deve ser curioso o suficiente para despertar a emoção, pois é com esta que “[...] se abrem as janelas da atenção, foco necessário para a construção do conhecimento" (MORA, 2013, p. 66).

Além do mais, pelo fato de também sermos alunos, compreendemos que a aprendizagem precisa provocar o interesse. É por isso que ela requer:

“[...] espaços de práticas frequentes (aprender fazendo) e de ambientes ricos em oportunidades [...]. A aprendizagem ativa aumenta a nossa flexibilidade cognitiva, que é a capacidade de alternar e realizar diferentes tarefas, operações mentais ou objetivos e de adaptar-nos a situações inesperadas, superando modelos mentais rígidos e automatismos pouco eficientes (BACICH; MORAN, 2018, p. 3).

Nesse caso, dizíamos em um de nossos relatos de vista à escola: Acreditamos que tudo que é novo, é sempre muito impactante. Assim, na aula regida no $1^{\circ} \mathrm{BD}$ esse impacto não foi diferente, apesar de que tenha sido menos impactante do que o esperado (Registro de 31/10/2018, p. 1).

Talvez o inesperado tenha sido o ponto chave da questão. Muito provavelmente o impacto foi menor justamente porque foi o primeiro contato, na posição de professora e, dito isso, automaticamente tentamos baixar o filtro afetivo ${ }^{2}$ para que pudéssemos viver a prática, observá-la e, posteriormente, autoavaliá-la conscientemente. Não sabemos exatamente até que ponto o registro demonstra a nossa curiosidade, inquietude e, quem sabe, até divertimento. Entretanto, queremos enfatizar o quanto a aprendizagem prática (ler-se ativa) pode ser capaz de nos ajudar a (re)adaptar as circunstâncias.

\footnotetext{
${ }^{2} \mathrm{O}$ filtro afetivo está ligado às emoções, podendo gerar motivação, ansiedade, autoconfiança, impedimento etc. Seu êxito depende de sua diminuição, caso contrário, o aprendiz poderá desenvolver bloqueio linguístico ou petrificação dos erros. Disponível em: https://profceciliafazzio.wordpress.com/2015/03/02/aprendizagem-atravesda-pnl-programacao-neurolinguistica/. Acesso em 10 de janeiro de 2019.
} 
Enfim, esclarecemos que o intuito desta seção foi expor o panorama geral de atividades que tivemos que desenvolver ao longo do projeto. Também caracteriza a nossa metodologia, já que "a pesquisa-ação é principalmente uma estratégia para o desenvolvimento de professores e pesquisadores de modo que eles possam utilizar suas pesquisas para aprimorar seu ensino e, em decorrência, o aprendizado de seus alunos" (TRIPP, 2005, p. 443), o que ressalta não só o objetivo do programa ao qual estávamos inseridos, mas também nos coloca como agentes da nossa própria formação e da formação de outros, os alunos. Passaremos para a próxima seção.

\section{Reflexões sobre o Residência Pedagógica na formação do professor de língua estrangeira}

As duas primeiras leituras realizadas dentro do programa Residência Pedagógica foram: (1) Residência Pedagógica: criando caminhos para o desenvolvimento profissional docente (COSTA; FONTOURA, 2015) e (2) O papel da observação de aulas durante o estágio supervisionado de Inglês (BIAZI; GIMENEZ; STUTS, 2015).

Na primeira leitura, as autoras (COSTA; FONTOURA, 2015) trazem reflexões ${ }^{3}$ acerca $^{2}$ da capacitação dos professores iniciantes que, muitas vezes, são recebidos sem apoio - seja por parte da escola ou, até, do professor-regente. Em função disso, ambas afirmam que a relação entre aquele que aprende (professor-aluno) e aquele que auxilia (professor-regente) é uma ótima oportunidade que pode possibilitar (novas) experiências de formação docente oriundas de reflexões, da convivência e do debate entre esses dois últimos.

Na segunda leitura, as autoras Biazi, Gimenez e Stuts (2015) pontuam questões relativas às experiências de observações de alguns professores que foram estagiários no final dos anos 80 e início dos anos 90. Estes professores estagiários discorrem sobre o repúdio em responder a questionários sobre observação, o que irá de acordo com as interpretações e os resultados obtidos na pesquisa: se observou, nas respostas dos professores estagiários e regentes entrevistados, a forte presença de avaliações metodológicas da prática do professor, como também se constata a resistência em não se aceitar estagiários - e sua regência em sala de aula

Trazendo para nossa realidade como AR na ECIT Bayeux, as reflexões idealizadas pelas autoras são primordiais para o nosso crescimento como professores em formação. Como já citado na introdução deste trabalho, a PP estabeleceu uma ponte entre nós e ela, o que nos

\footnotetext{
${ }^{3}$ As reflexões são resultados de uma pesquisa de mestrado sobre o programa Residência Pedagógica (RP), implementado no primeiro ano de estágio probatório para professores ingressantes na rede municipal de educação de Niterói, RJ, no ano de 2011. A pesquisa propõe uma reflexão sobre possibilidades e relevância dessa forma de inserção profissional docente, utilizando entrevistas (COSTA; FONTOURA, 2015).
} 
permite afirmar que não houve dificuldades relacionadas à falta de apoio da mesma, ou ainda da escola. Fomos e estamos sendo bem recebidos por toda a comunidade escolar (também incluímos aqui os alunos), inclusive estando aptos a sugestionar quaisquer melhorias.

Já na terceira e quarta leituras críticas, os dois textos lidos foram: (3) O ensino de línguas estrangeiras no contexto nacional (LEFFA, 1999) e (4) O ensino do espanhol no Brasil: presente, passado e futuro (MORENO FERNÁNDEZ, 2005).

A terceira leitura parte do contexto metodológico e político para refletir sobre o papel que ocupam as Línguas Estrangeiras (LEs) no atual sistema educacional brasileiro, buscando indicar possíveis soluções para o futuro.

Em razão disso, o autor ressalta a importância de olhar para o passado para que possamos compreender não apenas o futuro, mas também o presente, ressaltando que o conhecimento e o domínio tecnológico - após os Parâmetros Curriculares Nacionais - passou a ser um recurso bastante utilizado no ensino das LEs, o que propiciou "[...] um contexto favorável para a aprendizagem da língua estrangeira, veículo importante para a divulgação do conhecimento" (LEFFA, p. 30).

Na quarta leitura, Moreno Fernández (2005) apresenta um breve apanhado histórico e relata sobre o vínculo entre o nosso país e os países hispânicos. Posto isso, procura compreender quais os motivos que levam (ou levaram) ao aparecimento e ao uso da língua espanhola (LE) em nosso território.

O autor também acredita que a formação de professores de espanhol cresceu nos últimos anos, atribuindo a este acontecimento, feitos de natureza política, econômica e sociocultural que muito contribuíram e contribuem para a importância dessa língua no atual currículo da educação básica brasileira.

Assim, no que concerne a importância dessa língua, o quinto texto lido foi: Um olhar reflexivo sobre os Parâmetros Curriculares Nacionais de Língua Estrangeira (SILVA, 2012). Nesse artigo, a autora abre um diálogo baseado na discussão que gira em torno da necessidade de orientações curriculares unificadas que regulem o ensino de uma LE, nesse caso o inglês, na rede pública de ensino. Também salienta a importância do professor como agente ativo do processo educacional que deve possuir um olhar crítico diante da análise desse tipo de documento.

De acordo com isso, o estudo de línguas estrangeiras se associa - segundo os PCN - à política linguística de um país. No Brasil, por exemplo, o projeto de política linguística está direcionado à pluralidade linguística, embora na prática isso não ocorra efetivamente, como foi exposto no seguinte trecho: 
Uma primeira tentativa de aproximá-los da Língua Estrangeira é fazer com que se conscientizem da grande quantidade de línguas que os rodeia, em forma de publicações comerciais, de pôsteres, nas vitrinas das lojas, em canções, no cinema, em todo lugar. É verdade que o inglês predomina - e a consciência crítica dessa situação deve ser considerada -, mas há razoável quantidade do uso de outras línguas, tais como o italiano, o francês, o espanhol, o alemão, dependendo do contexto e das regiões. (BRASIL, 1998, p. 65)

É por essa razão que se torna importante refletir sobre o que os alunos fazem com o que aprendem, pois uma aprendizagem significativa também representa o entendimento do objeto de estudo em sua funcionalidade. Daí a necessidade de um olhar crítico do professor que não deve se restringir, apenas, ao ensino da língua meta, mas sim, refletir sobre a possibilidade de integrá-la e/ou multidiscipliná-la junto a realidade dos alunos.

No nosso contexto de observações, isso realmente é significativo para a PP, que sempre parte do conhecimento crítico acerca dos documentos pedagógicos que regem a ECIT Bayeux - relato de terceira visita à escola ${ }^{4}$-, procurando executar atividades que estabeleçam, de fato, a correlação entre teoria e prática (aqui enfatizamos, como exemplo, o uso do Livro Didático de Língua Espanhola (Cercanía joven ${ }^{5}$ ), que pouco é utilizado pela PP por que não contempla determinadas habilidades e/ou competências necessárias para uma efetiva aprendizagem de uma língua estrangeira).

Como vimos, não é apenas nas aulas de LE que isso ocorre, mas também, nos projetos e nas disciplinas eletivas ofertados pela escola. Nas palavras de Silva (2012, p. 2922), “a aprendizagem de outra língua implica diretamente no desenvolvimento da personalidade, uma vez que possibilita ao aluno ter contato com outros pontos de vista, outros costumes, diferentes valores e modos de interpretar o mundo."

Logo, falando em estabelecer esse contato com outros pontos de vista, lemos e discutimos sobre as Orientações Curriculares para o Ensino Médio (OCEM) com o intuito maior de ampliar a nossa própria visão de mundo. Como as demais leituras, essa nos suscitou reflexões profundas, pois o documento tem o objetivo de retomar a reflexão sobre a função educacional do ensino de LEs. É por isso que, talvez, essa tenha sido uma das leituras que mais nos impactou tendo em vista que sua natureza política nos coloca (pode nos colocar) de frente com nossas próprias ideologias.

\footnotetext{
${ }^{4}$ Disponível em: https://drive.google.com/open?id=1jL5bNhKRy-eCuUBCqZ iT8KazGdVrZYp. Acesso em 26 de outubro de 2017.

${ }^{5}$ Livro aprovado pelo Programa Nacional do Livro Didático (PNLD) para os anos de 2018, 2019 e 2020. O livro é de autoria de Ludmila Coimbra e de Luíza Santana Chaves.
} 
Considerando o papel educacional das LE conceituado ao longo das OCEM (BRASIL, 2006), é possível dizer que a visão de linguagem perde seu valor (quase) puramente linguístico para enveredar por uma abordagem que contemple, também, a formação humana e pedagógica do aluno. Sendo assim, enfatiza a noção de cidadania e a prática desta no ensino desses idiomas.

Buscando também (re)pensar uma nova visão de mundo, as OCEM trazem justificativas que nos incita a refletir sobre o papel da LE no ensino médio. Dessa forma, é dado ao valor social dessa aprendizagem um importante lugar a ser ocupado na sociedade, lugar esse que abrange todo o processo (didático-pedagógico) de conscientização entre o sujeito e o mundo.

É por isso que na perspectiva de inclusão as OCEM lembram da necessidade de políticas públicas para a infância e a adolescência, porém não se prendem a essa ideia. $\mathrm{O}$ foco trazido, por outro lado, diz que seria viável ensinar os alunos a entender as relações entre as disciplinas pedagógicas e a língua meta, como forma de "criar possibilidades de o cidadão dialogar com outras culturas sem que haja a necessidade de abrir mão de seus valores" (MATURANA, 1999). Ou seja, uma abordagem sociocultural.

Abrindo um parêntese, vale ressaltar que na escola de nossas observações, a relação das disciplinas pedagógicas com a língua meta e/ou outras disciplinas já foram (ou serão) citadas ao longo deste trabalho. No entanto, gostaríamos de exemplificar aqui que, no último relato ${ }^{6}$ de visita à escola, presenciamos uma apresentação teatro-musical para toda a comunidade escolar, que teve como tema o natal. Essa apresentação foi orientada por um professor da área técnica, valendo ressaltar que tudo foi planejado dentro de uma das eletivas da escola, a eletiva Casa da arte.

Isso, portanto, é resultado da união entre a área pedagógica e demais disciplinas e, a nosso ver, daí a parte inesperada de exposições dessa natureza - que geralmente estão focadas no aspecto religioso. A exposição mencionada, no entanto, saiu quase totalmente desse foco (no início, houve a aparição da virgem Maria como simbolização para o nascimento de Jesus) já que temas como feminismo, estrupo, uso de drogas, luxúria, bullying e problemas familiares receberam um especial enfoque junto a temática principal.

Fechando o parêntese, acreditamos que trabalhar essa cidadania proposta é trabalhar temas sensíveis ${ }^{7}$ dentro da realidade da vida cotidiana, tendo sempre a preocupação de que seja um momento de reflexão e não de imposição, assim como ter a cautela de abrandar a emissão

\footnotetext{
${ }^{6}$ Disponível em: https://drive.google.com/open?id=1z6HcbzVfXYcrsLy5-11fEGH3sYV9HEvk. Acesso em 09 de janeiro de 2019.

7 Aqui consideramos temas sensíveis as temáticas que abarcam diferentes simbologias e/ou significados, podendo levar o indivíduo a re(lembrar) certas memórias que podem ser felizes ou não.
} 
de emoções que poderão surgir ao longo do processo. Embora esse exemplo não esteja, especificamente, relacionado à disciplina de Língua Espanhola, o pontuamos como formação humana de subtemas trabalhados nesse idioma, no decorrer do ano de 2018. Podemos dizer, portanto, que houve a união entre o pedagógico e a LE.

Os Parâmetros Curriculares Nacionais do Ensino Médio (BRASIL, 2000) - reafirma a seriedade da função de se ensinar línguas tendo em vista que muito podem contribuir para as formações profissional, acadêmica e pessoal dos alunos do ensino médio.

Para cumprir com essas formações, o referido documento (p. 32) exemplifica a união das competências e habilidades para que se aprenda uma nova língua: (1) representação e comunicação => estudo da língua normativa; (2) investigação e compreensão => inferência do contexto de produção da língua meta; (3) contextualização sociocultural => compreensão da cultura do outro a partir de sua própria cultura.

Isso reafirma o que já narramos até aqui, uma vez que as habilidades e competências se relacionam, diretamente, com o sociocultural pontuado pelas OCEM, por exemplo. Ademais, no(s) exemplo(s) citado(s), podemos perceber esse diálogo visto que a escola, por ser cidadã, objetiva esse tipo de formação - que acreditamos estar cumprindo.

Para intensificar as questões discutidas até aqui, trazemos a Base Nacional Comum Curricular (BRASIL, 2018), ou BNCC, que é um documento que promete guiar o ensino básico a partir da integração de políticas nacionais da educação com outras políticas e ações, em âmbito federal, estadual e municipal. Para tanto, pretende desfragmentar essas políticas com o intuito de possibilitar uma educação baseada em competências gerais $^{8}$ e decisões pedagógicas orientadas para esse fim.

Conforme o exposto, o documento segue explicando e apontando caminhos que se dizem colaboradores para o desenvolvimento humano global - intelectual, físico, afetivo, social, ético, moral e simbólico - baseado nos pilares da educação e nas competências para o século XXI - que é um dos eixos da ECIT Bayeux.

Noutra perspectiva, a BNCC ressalta a formação de professores no ensino superior, uma vez que existem irregularidades nesse ensino e, assim, se faz necessário a tomada de providências para sua regulação. Segundo isso, pois, é necessário o preparo adequado para que o docente possa lidar e entender as culturas juvenis, como também viabilizar a proposta almejada. Daí por diante, vemos isso como justificativa, que dita de outra forma, ratifica a

\footnotetext{
8 "Na BNCC, competência é definida como a mobilização de conhecimentos (conceitos e procedimentos), habilidades (práticas, cognitivas e socioemocionais), atitudes e valores para resolver demandas complexas da vida cotidiana, do pleno exercício da cidadania e do mundo do trabalho" (BRASIL, 2018, p. 8, grifo nosso).
} 
postura procedimental do programa Residência Pedagógica, no que se refere a formação de professores.

Além disso, se observa, na teoria, uma postura metodológica e linguística plurais, o que ideologicamente promete integrar o estudo de várias outras Línguas Estrangeiras, além da Língua Inglesa - tida como língua de "comunicação global" (ver seção Competência Específica 4, p. 494). Assim, se fala em "direitos linguísticos", dando a escola a autonomia de implementar outras línguas, que não apenas o inglês, conforme suas necessidades locais, pois se compreende que assegurar o estudo de um único idioma como obrigatório é desconsiderar a pluralidade linguística e reduzir - é causar exclusão - o acesso, principalmente, a novas formas de apropriação do conhecimento, seja ele cultural ou instrumental.

É por isso que na escola de nossa vivência, isso ainda é um aspecto a ser reavaliado, já que só dispõe do ensino de Língua Inglesa e de Língua Espanhola quando, na realidade, já poderia ofertar uma outra língua, como o francês. O ensino de Língua Francesa se justificaria no fato de que o próprio município de Bayeux ${ }^{9}$ tem antepassados e vínculo com países que tem o francês como língua oficial, o que viabiliza a necessidade desse ensino.

Outro ponto crucial para finalizar nossas impressões acerca da BNCC, sobretudo no âmbito do ensino de Línguas Estrangeiras, diz respeito aos "Itinerários formativos", que funcionam como uma espécie de reorientação curricular para o Ensino Médio - divididos por áreas do conhecimento (linguagens e suas tecnologias, matemática e suas tecnologias, ciências da natureza e suas tecnologias, ciências humanas e sociais aplicadas e formação técnica e profissional). Aqui se dá ao aluno a escolha para trilhar pelas áreas ansiadas pelo seu próprio projeto de vida.

Voltando-nos para a nossa realidade, vemos algo semelhante nas disciplinas, nos projetos e nas eletivas ofertadas pela escola. Nelas, percebemos as oportunidades que os estudantes possuem para escolher o que lhe apetecem. Nas eletivas, a título de exemplo, os alunos podem mudar de projeto semestralmente e, com isso, experimentarem-se em diferentes áreas.

Em nossa opinião, as leituras supracitadas funcionaram como links de recordação que ativaram as nossas vivências pessoais como alunos, porque possibilitaram uma discussão rica desde o ponto de vista de cada um, em um determinado contexto. No papel de professores em formação, os links serviram como apoio teórico de outras leituras já realizadas na universidade,

\footnotetext{
${ }^{9}$ Disponível em: $<$ https://repositorio.ufpb.br/jspui/bitstream/123456789/658/1/GSF06082014.pdf $>$. Acesso em 20 de abril de 2019.
} 
além de extrapolarem o âmbito da teoria nas observações que estamos fazendo ao longo desse período de tempo.

Por essa razão, as leituras não estão favorecendo apenas a nossa bagagem cultural e profissional, mas também nos auxiliando a nos posicionar, de maneira empática, no lugar do outro que daqui a algum tempo será, de igual modo, o nosso lugar: o de professor observado.

Dessa forma, relataremos a seguir sobre a presença da disciplina de LE na grade curricular da escola referenciada no começo deste trabalho.

\section{Considerações finais}

Para concluir, relembramos os nossos objetivos iniciais: (i) narrar as atividades realizadas e (ii) refletir se o RP contribuiu com a formação do aluno de Letras-espanhol da UFPB. Ao cumprir o primeiro objetivo, expomos um panorama geral acerca das atividades realizadas durante a vigência do Residência Pedagógica. Em seguida, refletimos (em alguns momentos de forma mais implícita) sobre os resultados do primeiro objetivo. Em outras palavras, conseguimos, mesmo que de forma muito resumida, comprovar que o referido programa contribuiu, através de suas atividades, com a formação do aluno de licenciatura.

Deixamos claro que por mais que esta pesquisa não contemple uma maior extensão de detalhes e/ou arcabouço teórico - por uma questão de escolha, já que o nosso intuito era promover uma breve reflexão inicial acerca do supracitado programa como parte da formação do licenciando, em especial do aluno de Letras-espanhol da UFPB -, devemos considerar que a mesma pode suscitar várias indagações, o que é muito bom para um trabalho. Além do mais, não buscamos analisar dados, mas sim narrar (mesmo que de forma sucinta) e refletir, o que pode gerar confusões que podem atingir a compreensão de alguns leitores, uma vez que a maioria das pesquisas se medeiam por análise de dados.

Com base em um programa pioneiro, tais indagações podem mediar futuras discussões em relação a formação docente dos futuros professores de língua estrangeira. Isso valida o nosso artigo, como também o coloca em evidência, ao passo que contém informações relevantes para a área de formação docente e para o contexto de Ensino Médio-Integral-Técnico, o que pode significar uma abertura para a produção de um outro artigo.

Finalmente, narrar e refletir podem promover inúmeras interpretações para além daquelas que o pesquisador almeja. Também é possível visualizar acertos e falhas que precisam de melhoras no diz que diz respeito ao contexto específico. Nos resta, portanto, almejar bons 
frutos com a publicação deste artigo e, sobretudo, instituir diálogo acerca da formação de professores por meio do RP.

\section{Referências}

BACICH, L; MORAN, J. Metodologias ativas para uma educação inovadora: uma abordagem teórico-prática. Porto Alegre: Penso, 2018, p. 2-23.

BIAZI, Terezinha Marcondes Diniz; GIMENEZ, Telma; STUTS, Lídia. O papel da Observação de Aulas Durante o Estágio Supervisionado de Inglês. SIGNUM, Londrina, n. 14/1, p. 57-78, jun. 2011.

BRASIL. Ministério da Educação. Orientações Curriculares para o Ensino Médio (OCEM). Vol. 1. Linguagens, códigos e suas tecnologias. Brasília: Ministério da Educação/Secretaria de Educação Média e Tecnológica, 2006, p. 87-156.

BRASIL. Secretaria de Educação Básica. Ministério da Educação. Orientações Curriculares para o Ensino Médio - Linguagens, códigos e suas tecnologias. Brasília, 2006, p. 25-32.

BRASIL. Secretaria da Educação Fundamental. Parâmetros Curriculares Nacionais: terceiro e quarto ciclos do ensino fundamental: Língua Estrangeira. Brasília: MEC/SEF, 1998.

BRASIL. Base Nacional Comum Curricular (BNCC). Educação é a base. Brasília: MEC/CONSED/UNDIME, 2018. Disponível em: http://basenacionalcomum.mec.gov.br/wpcontent/uploads/2018/12/BNCC_19dez2018_site.pdf. Acesso em: 07 mai. 2019.

CAPES. Portaria GAB $\mathbf{N}^{\circ}$ 38, de 28 de fevereiro de 2018. Institui o Programa de Residência Pedagógica. Brasília: Capes, 2018.

COSTA, Luciana Laureano; FONTOURA, Helena Amaral da. Residência Pedagógica: criando caminhos para o desenvolvimento profissional docente. Ambiente Educação, São Paulo, v.9, n.2, p. 161-177, jul/dez. 2015.

LEFFA, Vilson J. O ensino de línguas estrangeiras no contexto nacional. Contexturas, APLIESP, n. 4, p. 13-34, 1999.

MATURANA, H. A ontologia da realidade. Belo Horizonte: UFMG (edição de referência: 2001), 1999.

MORA, E. Neuroeducación: sólo se puede aprender aquello que se ama. Madrid: Alianza Editorial, 2013.

MORENO FERNÁNDEZ, Francisco. El español en Brasil. In: SEDYCIAS, João (Org.). O ensino do espanhol no Brasil: presente, passado, futuro. São Paulo: Parábola, 2005.

SILVA, H. G. L. Um olhar reflexivo sobre os Parâmetros Curriculares Nacionais de Língua Estrangeira. In: CONGRESSO NACIONAL DE LINGUÍSTICA E FILOLOGIA, 16., 2012, Rio de Janeiro. Anais [...]. Rio de Janeiro: Universidade do Grande Rio, 2012. p. 2915-2928. 
TRIPP, David. Pesquisa-ação: uma introdução metodológica. Educação e Pesquisa, São Paulo, v. 31, n. 3, p. 443-466, set/dez. 2005.

RECEBIDO EM: 10/08/2020 ACEITO EM: 02/09/2020 